\title{
Aim and Design of pREGnant, the Dutch Pregnancy Drug Register
}

\author{
Saskia Vorstenbosch ${ }^{1}$ (1) $\cdot$ Bernke te Winkel ${ }^{1} \cdot$ Marleen M. H. J van Gelder ${ }^{2,3} \cdot$ Agnes Kant $^{1} \cdot$ Nel Roeleveld $^{2}$. \\ Eugène van Puijenbroek ${ }^{1,4}$
}

Published online: 24 September 2018

(c) The Author(s) 2018

\begin{abstract}
Information on the safety of medication use during pregnancy and breastfeeding is scarce, yet use of medication among pregnant and breastfeeding women is widespread. The pREGnant, the Dutch Pregnancy Drug Register, was set up to obtain insight into medication use among pregnant and breastfeeding women and potential effects on maternal and fetal/infant health. The systematically documented, good quality data on medication use during pregnancy and lactation in pREGnant will be used in signal detection, epidemiologic studies and counseling of healthcare providers and patients. The register has a prospective cohort design. The population is derived from pregnant women throughout the Netherlands. Data collection started in April 2014 and enrollment of women is continuous and is characterized by a relative high proportion of women born in the Netherlands with a high education compared with the general Dutch pregnant population. Data on current pregnancy, obstetric history, maternal lifestyle, health and medication use, delivery, and infant health are collected through web-based questionnaires completed by the participating women (three times during pregnancy and three times during the infant's first year of life). If permission is given, the self-reported data can be complemented with information retrieved from Perined, the perinatal registry of the Netherlands, and from obstetric and medical records, and/or pharmacy records. Here, we provide detailed information on the design of the pREGnant, the Dutch Pregnancy Drug Register, as well as descriptive information on characteristics of the participants so far. Currently, steps are being taken to implement the register on a large scale in the Netherlands.
\end{abstract}

Saskia Vorstenbosch

s.vorstenbosch@1areb.nl

1 Netherlands Pharmacovigilance Centre Lareb, Goudsbloemvallei 7, $5237 \mathrm{MH}$ 's-Hertogenbosch, The Netherlands

2 Department for Health Evidence, Radboud Institute for Health Sciences, Radboud University Medical Center, Nijmegen, The Netherlands

3 Radboud REshape Innovation Center, Radboud University Medical Center, Nijmegen, The Netherlands

4 PharmacoTherapy, -Epidemiology and -Economics, Groningen Research Institute of Pharmacy, University of Groningen, Groningen, The Netherlands

\section{Key Points}

The ultimate aim of the pREGnant, the Dutch Pregnancy Drug Register, is to provide practical recommendations for the pharmaceutical care of pregnant and postpartum women.

To obtain more knowledge on medication use among pregnant and breastfeeding women and potential effects on maternal and fetal/infant health, it is important to have well documented, high-quality data on exposures, outcomes, and covariables.

\section{Introduction}

When a medicine is marketed, information about its use during pregnancy and lactation is sparse and mostly limited to animal studies. Pre-marketing clinical trials do not include pregnant women, except when the product is specifically intended to be used in pregnancy [1]. Therefore, information 
on pregnancy and offspring outcomes as a result of medication use can only be acquired post-marketing when medication is used by pregnant women in daily practice [2-4]. Despite the lack of safety information, medication use among pregnant and breastfeeding women is widespread with prevalence estimates ranging between 40 and $96 \%$ of women taking at least one prescribed medication during pregnancy [5-9]. The lack of knowledge may hamper optimal treatment of pregnant and breastfeeding women as it might affect prescribing behavior of healthcare providers (HCPs) or adherence to the treatment [10, 11]. Certain maternal illnesses, however, pose a risk for maternal or fetal health without proper pharmacological treatment [12-18]. Due to unwarranted concerns, women might not try to get pregnant or pregnancies may be terminated unnecessarily, whereas fetal development in other pregnancies may be put at risk because of exposure to medication with unknown teratogenic effects $[11,19]$. In addition, neonates may not benefit from breastfeeding due to non-initiation or cessation when the mother needs medication [20,21].

Several established approaches are currently in place to increase the knowledge on the safety profile of medication use during pregnancy and lactation. While some of these are more appropriate to detect potential signals of safety concerns, others might be more suitable to perform exposure-outcome association studies [22]. Spontaneous reports of cases in pharmacovigilance databases are a valuable source when generating hypotheses and identifying highly teratogenic medications. Marketing authorization holders (MAHs) are obliged to monitor all pregnancies that are exposed to their product. They may also be requested to set up a pregnancy registry. Although these registries are of value for signal generation, their contribution to signal confirmation is limited due to, for instance, a large amount of missing data, high attrition rates, and the lack of appropriate controls [23]. Pharmacoepidemiologic studies to assess exposure-outcome associations need to make use of large datasets. Big data approaches using linkage of data readily available in healthcare databases are often population-based and have large sample sizes. As these data are not collected for research purposes, however, the quality of the data might be limited and important variables may be lacking (e.g., lifestyle factors, detailed information on exposure) [24-28]. The strength of non-selective case-control approaches, such as in the National Birth Defects Prevention Study (NBDPS) and the European surveillance of congenital anomalies (EUROCAT), is the high statistical power that enables the detection of teratogenic medication, even if the outcome is rare. However, information bias and in particular recall bias are a major threat to the validity of case-control studies [29-32].

In the Netherlands, no central database existed that documented relevant, good quality information to address a variety of questions regarding medication use during pregnancy and breastfeeding on a large scale in a systematic and continuous way. Therefore, we developed the pREGnant, the Dutch Pregnancy Drug Register. The ultimate aim of pREGnant is to obtain more insight into medication use among pregnant and breastfeeding women and safety aspects concerning maternal and fetal/infant health. In the present article, we provide detailed information on the design of pREGnant, as well as descriptive information on characteristics of the participants enrolled from April 1, 2014 until March 31, 2018, the effectiveness of several recruitment methods, and the follow-up rates. Also, the strengths and limitations of its design and future perspectives are discussed.

\section{Design of pREGnant}

\subsection{Target Population}

The target population of the pREGnant, the Dutch Pregnancy Drug Register, is pregnant women throughout the Netherlands (approximately 170,000 births/year) [33]. The inclusion criteria are (i) proficiency in the Dutch language and (ii) having access to the internet. The latter was true for over 99\% of Dutch women between 18 and 45 years in 2017 [34]. The only exclusion criterion is being under 18 years of age. We aim to enroll women in pREGnant as early in pregnancy as possible, although women can enroll at any time throughout the entire pregnancy. The use of medication at enrollment is no prerequisite, since women might use medication later in pregnancy or during the breastfeeding period. If not, they could be included in a reference group in future studies.

\subsection{Recruitment Methods}

Pregnant women are recruited in several ways. Both midwifes and gynecologists are asked to invite pregnant women at their first contact or first prenatal care visit, generally around gestational weeks $8-10$. These HCPs, as well as others (e.g., pharmacists, neurologists), can send pregnant women an automatically generated digital invitation through their account on the pREGnant website (https:// www.pregnant.nl). This personalized invitation is signed by the HCP and provides information on participation, including information that is needed for a woman to access the online informed consent form directly. Alternatively, the HCP hands out an information leaflet about the register, in which women are invited to participate. In that case, the woman can sign up on the pREGnant website. The information on the website is sufficient to inform the woman on what to expect when participating. In case of any remaining questions, she can get in touch with the pREGnant team by e-mail. HCPs who contact the Dutch Teratology Information 
Service (TIS) for telephone counseling are asked to inform their patients about participation in pREGnant as well. Moreover, the social networks of participants are used to enroll new participants. Pregnant women often know other pregnant women. After completion of a questionnaire, the participant is asked to send an invitation for the register to other pregnant women she knows, thereby increasing the number of participants without the intervention of HCPs.

Participants that use antiepileptic medication are asked permission to share their data with EURAP (European Registry of Antiepileptic Drugs and Pregnancy) and receive additional questions regarding their disease (e.g., occurrence of insults). EURAP is an international study on the risk of antiepileptic drug use during pregnancy [35]. In this collaboration, data for large numbers of women that use antiepileptic drugs during pregnancy are collected in a central database. The Dutch data collection for EURAP is embedded in pREGnant. To reach pregnant women with epilepsy, additional recruitment methods are employed. The national guideline for diagnosis and treatment of epilepsy encourages neurologists to discuss the importance of participation in the Dutch Pregnancy Drug Register and in that way contribute to EURAP as well [36]. Furthermore, recruitment is facilitated through promotion on the website of the patient organization for people with epilepsy and by publications in their magazine [37]. pREGnant is also promoted on certain websites of patient organizations of common chronic diseases in women of childbearing age, such as ulcerative colitis, Crohn's disease, and rheumatologic diseases. On the website of the Royal Dutch Pharmacists Association (KNMP) with medication information for the general public, the register is mentioned in the section about pregnancy and lactation of every medication [38]. The recruitment methods making use of an information leaflet or publicity on a website require that the woman sign up on the pREGnant website herself.

\subsubsection{Effectiveness of Recruitment Methods}

The majority of the current participants (64\%) were enrolled through a digital invitation they received from their HCP. The $36 \%$ of participants that signed up on the pREGnant website were informed about pREGnant through oral or written information from their $\mathrm{HCP}(76 \%)$, visiting a website on which pREGnant is promoted (11\%), a digital invitation from another participant (4\%), previous participation (3\%), or otherwise $(6 \%)$. Because of the different recruitment methods, the total number of pregnant women approached is unknown, so it is not possible to calculate the exact participation rate. In the pilot phase, however, the participation rates of some recruitment methods were assessed, being 33\% when HCPs sent a digital invitation, $16 \%$ when a digital invitation was sent by another participant, and $6 \%$ when the information leaflet was handed out or was displayed in the waiting area only [data not shown].

\subsection{Data Collection: Schedule}

The pREGnant, the Dutch Pregnancy Drug Register, started on April 1, 2014. Participants receive six web-based questionnaires in total, except for those who start participation after gestational week 20 (see below). Actual participation is preceded by completing an online informed consent form, in which consent is also asked for linkage of the questionnaire data to data from Perined, the perinatal registry of the Netherlands [39], obstetric and medical records, and/or pharmacy records. Participants receive a questionnaire at enrollment, in gestational week 17 , in gestational week 34 , and 2, 6, and 12 months after the expected date of delivery. When a questionnaire is due to be completed, the participant automatically receives an invitation by email. If she does not act on this invitation or does not fill out the questionnaire completely, a maximum of two reminders will be sent (with 6- and 12-day intervals for the questionnaires during and after pregnancy, respectively). Participation will automatically end when the questionnaire due is not completed within 30 days after the last reminder was sent, resulting in loss to follow-up of the participant. This means that it is not possible to skip a questionnaire, as this would result in missing data on relevant topics. The second questionnaire is the only exception to this rule, as it will be skipped in case of enrollment after gestational week 20 and does not gather data on topics that are not covered in the other questionnaires.

When a miscarriage, elective termination, or stillbirth is reported, the questionnaire is adjusted accordingly to obtain just a minimal set of data and participation is ended automatically. HCPs or participants may also notify the pREGnant team about adverse outcomes by email. In that case, participation is ended manually, the reason for attrition is documented, and no further questionnaires are sent. When participants are lost to follow-up or when a clinical situation needs clarification (e.g., maternal disease or birth defect), data can be supplemented with data from other sources. Of all participants who completed the consent form and the first questionnaire, $88.2 \%, 71.7 \%$, and $68.3 \%$ gave permission to obtain additional data from Perined, the perinatal registry of the Netherlands [39], from obstetric and medical records, and from pharmacy records, respectively.

\subsubsection{Number of Participants and Follow-Up Rates}

Figure 1 shows the number of invitations sent per questionnaire as well as the number of participants that completed the particular questionnaires by March 31, 2018. Because of the long period of time in which women are asked to 


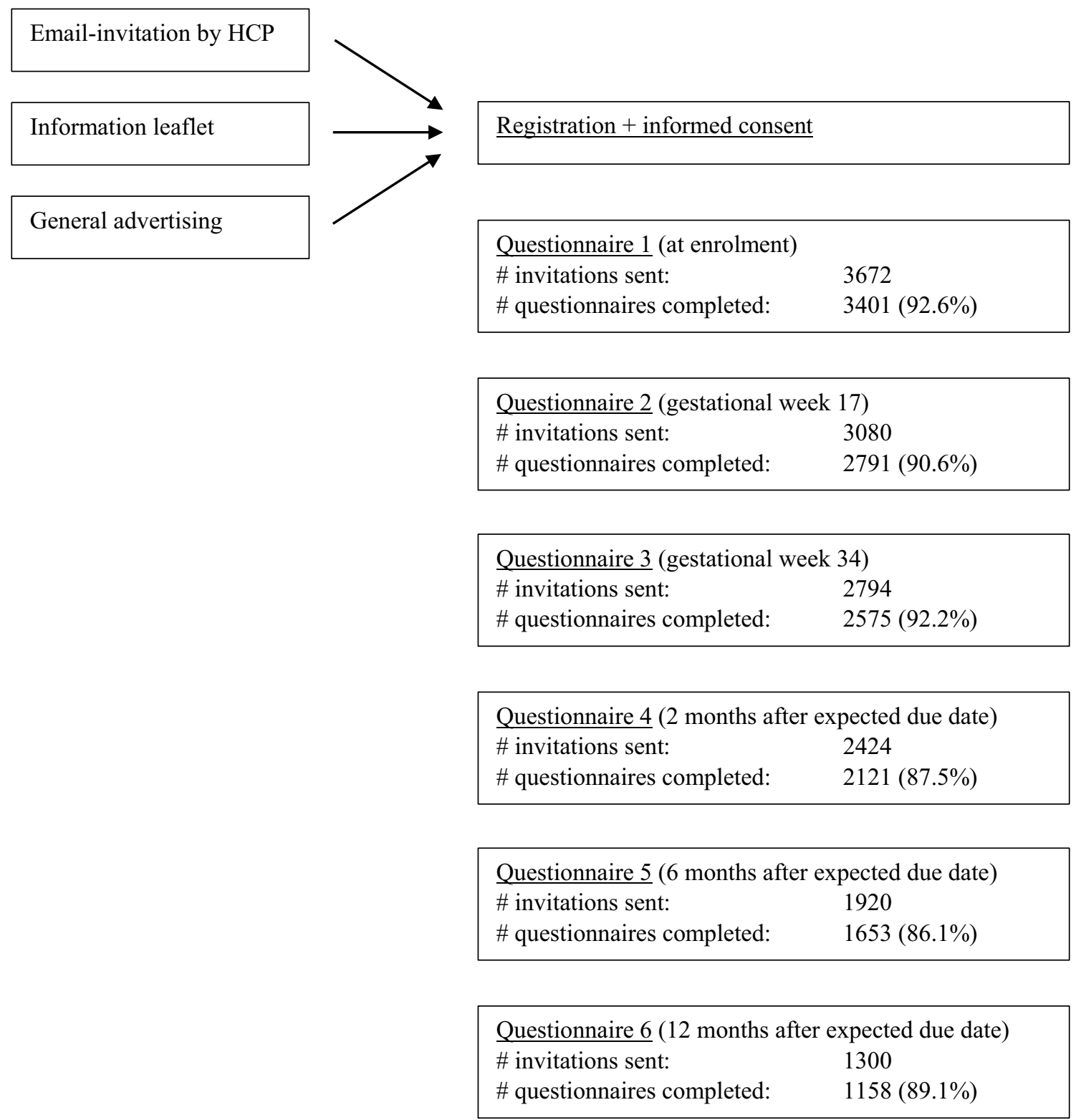

Fig. 1 Scheme depicting recruitment and follow-up in the pREGnant, the Dutch Pregnancy Drug Register. Status as of March 31, 2018. HCP healthcare provider

complete questionnaires (from beginning of pregnancy until the infant is 1 year of age), many participants are still pending. Loss to follow-up ranged from 7.4 to $13.9 \%$ per questionnaire. This may be due to a change of email-address, no interest in participating any longer, self-initiated withdrawal because of an adverse outcome, or other reasons.

\subsection{Data Collection: Content}

Table 1 provides an overview of the different topics on which information is being collected in pREGnant. In all questionnaires that concern the pregnancy or breastfeeding period, data on maternal health, medication use, and other potential determinants of adverse outcomes are collected. In case of multiple answer options, checkbox lists are shown, always with the possibility of entering additional information in a free-text field. When possible, information already provided in a previous questionnaire is shown and participants are asked to verify if the information is still accurate or needs elaboration.

Since the outcome measures of interest are, among others, pregnancy outcome (miscarriage, elective termination, stillbirth, or live birth), birth defects, gestational age, birth weight, and effects of medication use during breastfeeding, information on these topics is collected as well. 


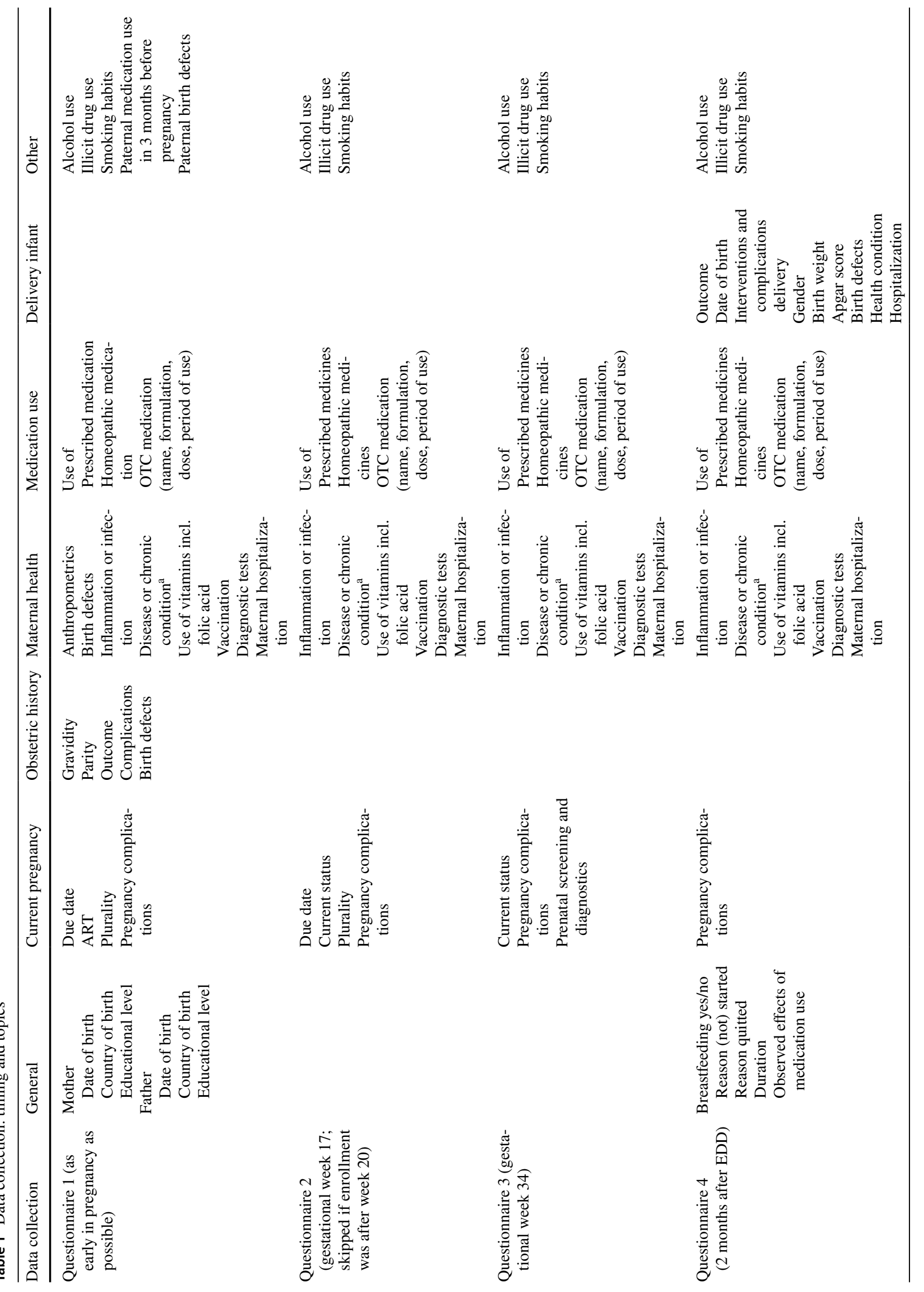




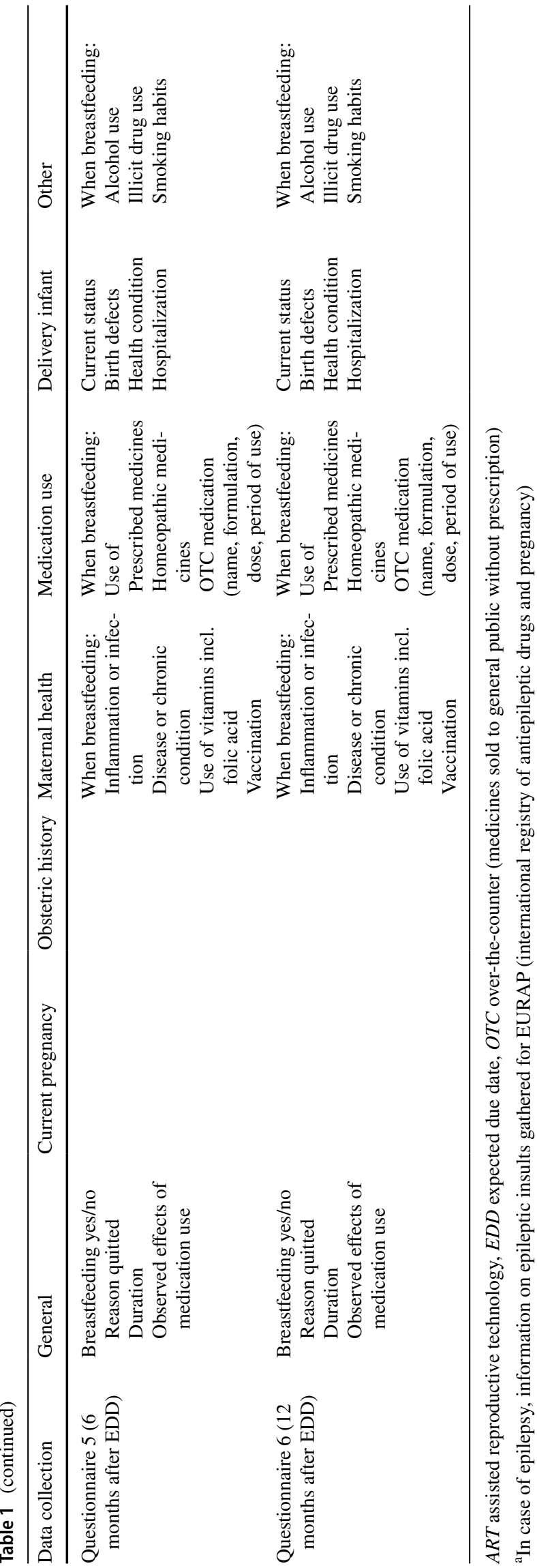

Medication use is asked about in an indication-oriented manner to enhance maternal recall [40, 41]. Participants first select relevant indications from predefined lists, which is followed by showing specific medication names for the selected indication(s). Based on the medication name that is chosen, tailored multiple-choice questions about formulation, dosage, and period of use are shown. When a participant used a medication that is not shown (e.g., off-label use), they can provide the medication name and the subsequent information on formulation, dosage, and period of use as open text. In this way, prescribed, over-the-counter medications, and non-registered medications can be reported.

\section{Characteristics of Participants}

Table 2 shows the general characteristics of the participants included in the pREGnant, the Dutch Pregnancy Drug Register, from April 1, 2014 through March 31, 2018. At that time, 3401 pregnant women were enrolled and had completed at least the first questionnaire. The characteristics of the participants at baseline were compared with those of women that gave birth in 2015 or with women of childbearing age in the Netherlands in 2016 [42-44]. Participants in pREGnant were more often highly educated and had a higher maternal age at the expected date of birth than the entire Dutch pregnant population. Maternal country of birth differed as well, as participants were more often born in the Netherlands. In the first questionnaire, $63.5 \%$ of the participants reported the use of at least one medication during their pregnancy up to completion of the questionnaire (median: gestational week 10.7). Of these women, 1167 (54.0\%) reported the use of more than one type of medication. Table 3 shows the individual medication names that were reported by at least $2 \%$ of the participants in the first questionnaire. Of the 12 most commonly reported medications, seven were available over the counter, with acetaminophen use being reported by $21.1 \%$ of the pregnant women.

\section{Establishment of the Design}

The design of the Dutch Pregnancy Drug Register was established during a pilot phase, in which it was evaluated, optimized, and organized in a sustainable way to ensure ongoing enrollment and good quality data collection. Based on feedback from participants and HCPs, the content and clarity of the questionnaires are being evaluated at regular intervals. Initially, the PRegnancy and Infant DEvelopment (PRIDE) study, coordinated by the Radboud university medical center [45], served as a template for the pREGnant, the Dutch Pregnancy Drug Register, as it has a comparable web-based approach to obtaining information on a broad 
Table 2 Characteristics of women enrolled in the pREGnant, the Dutch Pregnancy Drug Register, from April 1, 2014 through March 31 , 2018 compared with Dutch women who gave birth in 2015 or Dutch women of childbearing age in 2016

\begin{tabular}{|c|c|c|c|c|}
\hline & & \multicolumn{2}{|c|}{ Participants in pREGnant $(N=3401)$} & \multirow{2}{*}{$\begin{array}{l}\text { General population of } \\
\text { Dutch women } \\
\%\end{array}$} \\
\hline & & $N$ & $\%$ & \\
\hline \multicolumn{5}{|l|}{ Maternal age $^{\mathrm{a}}$} \\
\hline 18-19 years & & 1 & 0.0 & $1.0^{\mathrm{b}}$ \\
\hline $20-24$ years & & 129 & 3.8 & $9.3^{\mathrm{b}}$ \\
\hline $25-29$ years & & 913 & 26.8 & $30.9^{\mathrm{b}}$ \\
\hline $30-34$ years & & 1617 & 47.5 & $38.1^{\mathrm{b}}$ \\
\hline $35-39$ years & & 666 & 19.6 & $17.6^{\mathrm{b}}$ \\
\hline$\geq 40$ years & & 74 & 2.2 & $3.2^{\mathrm{b}}$ \\
\hline Unknown & & 1 & 0.0 & \\
\hline \multicolumn{5}{|l|}{ Maternal country of birth } \\
\hline The Netherlands & & 3218 & 94.6 & $74.0^{\mathrm{b}}$ \\
\hline Other & & 170 & 5.0 & $26.0^{\mathrm{b}}$ \\
\hline Missing & & 13 & 0.4 & \\
\hline \multicolumn{5}{|l|}{ Maternal level of education } \\
\hline Low & & 99 & 2.9 & $11.7^{\mathrm{c}}$ \\
\hline Intermediate & & 919 & 27.0 & $37.4^{\mathrm{c}}$ \\
\hline High & & 2370 & 69.7 & $49.4^{\mathrm{c}}$ \\
\hline Unclassifiable & & 3 & 0.1 & \\
\hline Missing & & 10 & 0.3 & \\
\hline \multicolumn{5}{|l|}{ Pre-pregnancy BMI } \\
\hline$\leq 24.9 \mathrm{~kg} / \mathrm{m}^{2}$ & & 2182 & 64.2 & $60.4^{\mathrm{d}}$ \\
\hline$>25.0$ & & 820 & 24.1 & $39.6^{\mathrm{d}}$ \\
\hline Missing & & 399 & 11.7 & \\
\hline \multicolumn{5}{|l|}{ Parity } \\
\hline Primiparae & & 1760 & 51.7 & $44.6^{\mathrm{b}}$ \\
\hline Multiparae & & 1638 & 48.2 & $55.4^{\mathrm{b}}$ \\
\hline Missing & & 3 & 0.1 & \\
\hline \multicolumn{5}{|l|}{ Fertility treatment } \\
\hline Yes & & 275 & 8.1 & $4.7^{\mathrm{b}}$ \\
\hline No & & 3124 & 91.9 & $67.4^{\mathrm{b}}$ \\
\hline Missing & & 2 & 0.1 & $27.8^{\mathrm{b}}$ \\
\hline \multicolumn{5}{|l|}{ Plurality $(N=2911)$} \\
\hline Singleton & & 2819 & 96.8 & $98.3^{\mathrm{b}}$ \\
\hline Multiple & & 36 & 1.2 & $1.7^{\mathrm{b}}$ \\
\hline Unknown & & 2 & 0.1 & \\
\hline Missing & & 54 & 1.9 & \\
\hline Permission linkage with perined & & 3001 & 88.2 & \\
\hline Permission review medical/obst & ic records & 2440 & 71.7 & $98.3^{\mathrm{b}}$ \\
\hline Permission review pharmacy rec & & 2324 & 68.3 & $1.7^{\mathrm{b}}$ \\
\hline & Median & \multicolumn{2}{|c|}{ Q1-Q3 } & \\
\hline Gestational week at enrollment & 10.7 & \multicolumn{2}{|c|}{$8.9-13.3$} & \\
\hline
\end{tabular}

$B M I$ body mass index

a Maternal age at expected due date

${ }^{b}$ Data retrieved from Perined, the perinatal registry of the Netherlands regarding perinatal care, report 2015 (pregnant women) (17)

${ }^{\mathrm{c}}$ Data from the Centre for Policy-related Statistics (CBS), 2016, women aged 25-35 years (not pregnant) (18)

${ }^{\mathrm{d}}$ Data from the Centre for Policy-related Statistics (CBS), 2016, women aged 30-40 years (not pregnant) (19) 
Table 3 Individual medication names for which use during pregnancy was reported in the first questionnaire by at least $2 \%$ of the participants

\begin{tabular}{|c|c|c|}
\hline \multirow[t]{2}{*}{ Medication name } & \multicolumn{2}{|c|}{ Participants } \\
\hline & $N$ & $(\%)$ \\
\hline Acetaminophen $^{\mathrm{a}}$ & 719 & $(21.1)$ \\
\hline Meclozine/pyridoxine & 197 & $(5.8)$ \\
\hline Xylometazoline $^{\mathrm{a}}$ & 154 & $(4.5)$ \\
\hline Lamotrigine $^{\mathrm{b}}$ & 152 & $(4.5)$ \\
\hline $\begin{array}{l}\text { Calciumcarbonate/magnesiumcarbonate } \\
\left(\text { Rennie }^{\circledR}\right)^{\mathrm{a}}\end{array}$ & 136 & $(4.0)$ \\
\hline Levothyroxine & 116 & $(3.4)$ \\
\hline Levetiracetam $^{\text {b }}$ & 100 & $(2.9)$ \\
\hline Salbutamol & 88 & $(2.6)$ \\
\hline Cetirizine $^{\mathrm{a}}$ & 72 & $(2.1)$ \\
\hline Macrogol (and combination products) ${ }^{\mathrm{a}}$ & 70 & $(2.1)$ \\
\hline Omeprazole $^{c}$ & 69 & $(2.0)$ \\
\hline Aciclovir $^{\mathrm{a}}$ & 68 & $(2.0)$ \\
\hline
\end{tabular}

${ }^{\mathrm{a}}$ Over-the-counter medication

${ }^{b}$ The Dutch data collection for European Registry of Antiepileptic Drugs and Pregnancy (EURAP), an international registry of antiepileptic drugs and pregnancy, is embedded in pREGnant (35)

${ }^{\mathrm{c}}$ Over-the-counter as well as prescribed medication

range of potential risk factors, including medication use, and pregnancy and offspring outcomes. However, the PRIDE study has broader objectives and a longer follow-up period, and recruitment of participants will end in due time. Within the framework of the grant to establish the Dutch Pregnancy Drug register, several validation studies were performed to assess the merits of the methodology and the quality of the data collection [46-48]. Because pREGnant required a substantial period of preparatory work before actual recruitment of participants, these validation studies were mainly performed within the PRIDE study, but the results are applicable to pREGnant as well.

\subsection{Data Validation}

One of the validation studies showed that web-based questionnaires completed by pregnant women seem to be a valid method to obtain data on chronic disorders and allergies with equal or better data quality compared with obstetric records [46]. Another validation study showed that perinatal outcomes, such as gestational age and birth weight, were reported well in the web-based maternal questionnaires and showed only minor discrepancies with obstetric records [47]. The web-based data collection on medication exposure during pregnancy was validated by comparing the web-based questionnaires of both pREGnant and the PRIDE study with paper-based medication diaries that were completed by the participants over a period of 6 weeks as reference standard.
The degree of under-reporting in the web-based questionnaires was limited for a large number of medication groups used for chronic or pregnancy-related conditions. Medications for occasional and short-term use were under-reported more frequently. However, the sensitivity of most medications in the web-based questionnaires with indicationdirected questions was higher compared with paper-based data collection efforts [48]. In addition, detailed information on medication use is obtained through the web-based questionnaires, including data on indication for use, dose, formulation, and moment or period of exposure.

\section{Strengths and Limitations of the Design}

The main strengths of the Dutch Pregnancy Drug Register are the nature and quality of the data. The web-based data collection has several advantages over paper-based data collection: data entry errors are limited by the use of validation rules on data fields, and the willingness to report sensitive information may be increased [49, 50]. User friendliness is high, as questions are shown conditionally on former answers, and a subset of previously reported information is transferred to the next questionnaire.

Exposure data cover prescribed medication as well as over-the-counter medication and non-registered medications. For medication available without prescription, even fewer studies are available regarding use during pregnancy [25, 51-53]. As the woman herself is the main source of data, detailed information on the use of all kinds of medication is reported, and data on actual use (i.e., compliance) and exact timing of medication use are obtained as well. In pREGnant, maternal recall is enhanced by indication-oriented questions as recommended in previous studies [40]. As shown in our validation study, pregnant women report their medication use reliably for most medication groups [48], which is important when studying associations between medication exposure during pregnancy and potential adverse outcomes.

The design allows for different outcome parameters to be studied. Besides birth defects, other study outcomes of interest include birth weight and gestational age at birth, which were found to be of good quality [47]. Follow-up until the infant is 1 year of age allows for a more complete registration of the total number of birth defects compared with the short-term follow-up available in obstetric records and most birth registries [54, 55]. Estimates from EUROCAT NorthNetherlands showed that up to $95 \%$ of birth defects were diagnosed within the first year (de Walle $\mathrm{H}$, personal communication). Concomitantly, the follow-up period of $\mathrm{pREG}$ nant offers the opportunity to get more insight into decisions made concerning breastfeeding and medication use, as well as into the occurrence of adverse effects in the infant related to maternal medication use in this period. Currently, 
long-term outcomes, such as developmental milestones and neurodevelopmental disorders, are not part of pREGnant.

Despite the importance of including data on potential confounding factors in epidemiologic analyses, this information is lacking in various studies [56-61]. pREGnant has the advantage that data on a wide range of potential confounding factors are collected directly from the participants. Information is obtained on lifestyle factors, including smoking habits, use of alcohol, illicit drug use, and intake of folic acid and other food supplements, as well as on chronic conditions, pregnancy complications, and the indications for medication use. Furthermore, information on demographics, such as maternal age, educational level, and country of birth are obtained.

The pREGnant, the Dutch Pregnancy Drug Register, targets the entire Dutch pregnant population. The pREGnant cohort consists of women with and without specific medication use or diseases and allows the selection of suitable reference groups for different research questions. Currently, the participants form only a small percentage of the target population, and representativeness for the general pregnant population in the Netherlands is limited (Table 2). Initiatives are taken to increase the coverage (see future directions in Sect. 7), but selective participation cannot be prevented completely. The influence of selective participation will most likely be reflected in the maternal variables [62-65]. Selective loss to follow-up may, for instance, occur when women with an adverse outcome may be more prone to drop out or could be more motivated to report this outcome. Alternatively, women who face dilemmas concerning medication use during pregnancy or breastfeeding might be more motivated to start and/or keep participating [66, 67]. However, selective participation is not expected to have large effects on exposure-outcome associations directly, and potential confounding factors that may differ between pREGnant participants and the general population can be included in the analyses. Currently, we have no insight into whether the outcome measures of the women remaining in the register differ from the ones that are lost to follow-up. However, the missing data from participants that were lost to follow-up may partially be supplemented by retrieving data from other sources. If a woman gave permission, data on the pregnancy and outcome can be obtained from Perined and obstetric or medical records, and data on prescribed medication can be obtained from pharmacy records. A limitation of the pREGnant design is under-representation in pregnancies that end in an early miscarriage, resulting from enrollment of participants throughout pregnancy.

The Dutch Pregnancy Drug Register will not only provide data on potential adverse effects associated with medication use during pregnancy and breastfeeding, but will also provide data that support rational use. The approach ensures frequent reporting of commonly used medication among pregnant and breastfeeding women. The knowledge on the benefits and potential risks for maternal and fetal/infant health that will be obtained will therefore be relevant for public health. Since limited numbers of pregnancies are exposed to rarely used medications and specific birth defects occur at low frequency, one of the weaknesses of the register is the relative low number of participants at this time, which gives rise to a lack of statistical power to perform association studies on these medications and outcomes. This stresses the importance of large-scale implementation in the Netherlands and international collaboration [68].

\section{Applicability of the Data from the Register}

The data in the Dutch Pregnancy Drug Register provide an excellent opportunity to perform exposure-outcome association studies for commonly used medications during pregnancy and breastfeeding. Also, the data will be evaluated periodically to screen for potential adverse events resulting from medication use during pregnancy or breastfeeding. Proper risk assessment regarding medication use during pregnancy and breastfeeding is often complicated by the lack of evidence-based data. The well documented cases in pREGnant offer a way to support the counseling of HCPs by the Dutch TIS, thereby allowing more rational use of medication during pregnancy and breastfeeding [69].

\section{Future Directions}

The pREGnant, the Dutch Pregnancy Drug Register, was developed, validated, and evaluated in recent years. Currently, steps are being taken to implement pREGnant on a large scale in the Netherlands. As enrollment of pregnant women is most efficient when HCPs actively invite them for participation, this requires some additional effort by the HCP. The current approach may not be feasible in the long run. Therefore, with input from our advisory committee consisting of experts in the field of prenatal care, efforts are being made to integrate sending of the digital invitation for pREGnant into the midwives' digital practice information systems, thereby embedding pREGnant within the routine of prenatal care in the Netherlands.

At the moment, the indication for medication use is reported. As the severity of maternal disease is an important confounding factor for several outcome parameters, the possibility to document disease severity accurately will be explored. Data on long-term outcomes, such as developmental milestones and neurodevelopmental disorders, may be added to the data collection of pREGnant in the future as well. 


\section{Collaboration}

Researchers interested in collaboration, using the infrastructure, or performing a study with data from pREGnant are welcome to contact the principal investigator (info@pregnant.nl). For further questions or more information, please contact us through this email address as well.

The current dataset may already contain all data required to answer certain research questions. The flexibility within the IT application, however, also facilitates the inclusion of tailor-made questions for a specific subpopulation, or extensions of the data collection for a limited period of time. Therefore, if additional information is desired, data collection may be extended temporarily or data could be obtained through linkage with other sources. For applications, we request a short proposal including background information, a clearly defined research question, a plan for analysis, a time schedule, and a publication plan. The scientific advisory board of pREGnant will review the proposal. When approved, the mutual agreements will be formalized in a contract.

\section{Conclusion}

The pREGnant register is well established and validated. The current focus is increasing the number of participants by implementing the register on large scale.

\section{Compliance with Ethical Standards}

Funding This work was supported by the Netherlands Organization for Health Research and Development (ZonMw) (Grant number $836012001)$

Conflict of interest Authors Saskia Vorstenbosch, Bernke te Winkel, Marleen MHJ van Gelder, Agnes Kant, Nel Roeleveld, and Eugène van Puijenbroek declare that they have no conflict of interest.

Ethical approval All procedures performed in studies involving human participants were in accordance with ethical standards of the institutional and/or national research committee and with the 1964 Helsinki declaration and its later amendments or comparable ethical standards. The Regional Committee on Research Involving Human Subjects, Arnhem-Nijmegen, judged that the pREGnant, the Dutch Pregnancy Drug Register, does not require specific ethical approval since it collects data by means of questionnaires and existing data sources only.

Informed consent Online informed consent was obtained from all individual participants included in the Dutch Pregnancy Drug Register pREGnant.

Open Access This article is distributed under the terms of the Creative Commons Attribution-NonCommercial 4.0 International License (http://creativecommons.org/licenses/by-nc/4.0/), which permits any noncommercial use, distribution, and reproduction in any medium, provided you give appropriate credit to the original author(s) and the source, provide a link to the Creative Commons license, and indicate if changes were made.

\section{References}

1. Shields KE, Lyerly AD. Exclusion of pregnant women from industry-sponsored clinical trials. Obstet Gynecol. 2013;122(5):1077-81.

2. Briggs GG, Polifka JE, Wisner KL, Gervais E, Miller RK, Berard A, et al. Should pregnant women be included in phase IV clinical drug trials? Am J Obstet Gynecol. 2015;213(6):810-5.

3. Adam MP, Polifka JE, Friedman JM. Evolving knowledge of the teratogenicity of medications in human pregnancy. Am J Med Genet C Semin Med Genet. 2011;157C(3):175-82.

4. Rodger MA, Makropoulos D, Walker M, Keely E, Karovitch A, Wells PS. Participation of pregnant women in clinical trials: will they participate and why? Am J Perinatol. 2003;20(2):69-76.

5. Bakker MK, Jentink J, Vroom F, van den Berg PB, de Walle HEK, de Jong-van den Berg LT. Drug prescription patterns before, during and after pregnancy for chronic, occasional and pregnancy-related drugs in the Netherlands. Bjog. 2006;113(5):559-68.

6. Cleary BJ, Butt H, Strawbridge JD, Gallagher PJ, Fahey T, Murphy DJ. Medication use in early pregnancy-prevalence and determinants of use in a prospective cohort of women. Pharmacoepidemiol Drug Saf. 2010;19(4):408-17.

7. Crespin S, Bourrel R, Hurault-Delarue C, Lapeyre-Mestre M, Montastruc JL, Damase-Michel C. Drug prescribing before and during pregnancy in South West France: a retrospective study. Drug Saf Int J Med Toxicol Drug Exp. 2011;34(7):595-604.

8. Irvine L, Flynn RWV, Libby G, Crombie IK, Evans JMM. Drugs dispensed in primary care during pregnancy: a record-linkage analysis in tayside, Scotland. Drug Saf. 2010;33(7):593-604.

9. Mitchell AA, Gilboa SM, Werler MM, Kelley KE, Louik C, Hernandez-Diaz S. Medication use during pregnancy, with particular focus on prescription drugs: 1976-2008. Am J Obstet Gynecol. 2011;205(1):51.e1-8.

10. Lupattelli A, Spigset O, Nordeng H. Adherence to medication for chronic disorders during pregnancy: results from a multinational study. Int J Clin Pharm. 2014;36(1):145-53.

11. Matsui D. Adherence with drug therapy in pregnancy. Obstet Gynecol Int. 2012;2012:796590.

12. Accortt EE, Cheadle AC, Dunkel SC. Prenatal depression and adverse birth outcomes: an updated systematic review. Matern Child Health J. 2015;19(6):1306-37.

13. Bansil P, Kuklina EV, Meikle SF, Posner SF, Kourtis AP, Ellington SR, et al. Maternal and fetal outcomes among women with depression. J Womens Health. 2010;19(2):329-33.

14. Tennant PWG, Glinianaia SV, Bilous RW, Rankin J, Bell R. Preexisting diabetes, maternal glycated haemoglobin, and the risks of fetal and infant death: a population-based study. Diabetologia. 2014;57(2):285-94.

15. Bhowmik B. First Trimester complications in pregnancy with diabetes. J Pak Med Assoc 2016;66(Suppl 1)(9):S78-S80.

16. Van Der Woude CJ, Kolacek S, Dotan I, Oresland T, Vermeire S, Munkholm P, et al. European evidenced-based consensus on reproduction in inflammatory bowel disease. J Crohns Colitis. 2010;4(5):493-510.

17. Shand AW, Chen JS, Selby W, Solomon M, Roberts CL. Inflammatory bowel disease in pregnancy: a populationbased study of prevalence and pregnancy outcomes. BJOG. 2016;123(11):1862-70. 
18. de Jong PH, Dolhain RJ. Fertility, pregnancy, and lactation in rheumatoid arthritis. Rheum Dis Clin N Am. 2017;43(2):227-37.

19. de Santis M, Straface G, Cavaliere AF, Cinque B, Carducci B, Caruso A. Teratological risk evaluation and prevention of voluntary abortion. Minerva Ginecol. 2006;58(2):91-9.

20. Schirm E, Schwagermann MP, Tobi H, de Jong-van den Berg LT. Drug use during breastfeeding. A survey from the Netherlands. Eur J Clin Nutr. 2004;58(2):386-90.

21. Spiesser-Robelet L, Brunie V, de Andrade V, Gagnayre R. Knowledge, representations, attitudes, and behaviors of women faced with taking medications while breastfeeding. J Hum Lact. 2017;33(1):98-114.

22. Benevent J, Montastruc F, Damase-Michel C. The importance of pharmacoepidemiology in pregnancy-implications for safety. Expert Opin Drug Saf. 2017;16(10):1181-90.

23. Khromava A, Cohen CJ, Mazur M, Kanesa-thasan N, Crucitti A, Seifert H. Manufacturers' postmarketing safety surveillance of influenza vaccine exposure in pregnancy. Am J Obstet Gynecol. 2012;207(3 Suppl):S52-6.

24. Berard A, Sheehy O. The Quebec Pregnancy Cohort-prevalence of medication use during gestation and pregnancy outcomes. PLoS One. 2014;9(4):e93870.

25. Stephansson O, Granath F, Svensson T, Haglund B, Ekbom A, Kieler H. Drug use during pregnancy in Sweden-assessed by the Prescribed Drug Register and the Medical Birth Register. Clin Epidemiol. 2011;3:43-50.

26. Colvin L, Slack-Smith L, Stanley FJ, Bower C. Pharmacovigilance in pregnancy using population-based linked datasets. Pharmacoepidemiol Drug Saf. 2009;18(3):211-25.

27. Lacroix I, Hurault C, Sarramon MF, Guitard C, Berrebi A, Grau M, et al. Prescription of drugs during pregnancy: a study using EFEMERIS, the new French database. Eur J Clin Pharmacol. 2009;65(8):839-46.

28. Andrade SE, Berard A, Nordeng HM, Wood ME, Van Gelder MMHJ, Toh S. Administrative claims data versus augmented pregnancy data for the study of pharmaceutical treatments in pregnancy. Curr Epidemiol Rep. 2017;4(2):106-16.

29. Dolk H. Preventing birth defects: the value of the NBDPS case-control approach. Birth Defects Res A Clin Mol Teratol. 2015;103(8):670-9.

30. Reefhuis J, Gilboa SM, Anderka M, Browne ML, Feldkamp ML, Hobbs CA, et al. The national birth defects prevention study: a review of the methods. Birth Defects Res A Clin Mol Teratol. 2015;103(8):656-69.

31. Given JE, Loane M, Luteijn JM, Morris JK, de Jong van den Berg LT, Garne E, et al. EUROmediCAT signal detection: an evaluation of selected congenital anomaly-medication associations. Br J Clin Pharmacol. 2016;82(4):1094-109.

32. Czeizel AE. First 25 years of the Hungarian congenital abnormality registry. Teratology. 1997;55(5):299-305.

33. Statline Database. Birth; key figures [website Statistics Netherlands] 2017. http://statline.cbs.nl/statweb/publicatio $\mathrm{n} / ? \mathrm{vw}=\mathrm{t} \& \mathrm{dm}=\mathrm{s} \ln 1 \& \mathrm{pa}=37422 \mathrm{ned} \& \mathrm{~d} 1=0$. Accessed June 2018.

34. Statline Database. Internet; acces, use and facilities [website Statistics Netherlands] 2017. http://statline.cbs.n1/Statweb/publi cation/?DM $=$ SLNL\&PA $=83429 \mathrm{NED} \& \mathrm{D} 1=0,32 \& \mathrm{D} 2=0,2,8$ $10 \& \mathrm{D} 3=0 \& \mathrm{D} 4=1 \& \mathrm{HDR}=\mathrm{T} \& \mathrm{STB}=\mathrm{G} 1, \mathrm{G} 2, \mathrm{G} 3 \& \mathrm{VW}=\mathrm{T}$. Accessed June 2018.

35. Website of EURAP; International Registry of Antiepileptic Drugs and Pregnancy. http://www.eurapinternational.org/. Accessed June 2018.

36. Guideline Epilepsy, pregnancy and hormones of the Netherlands Association of Neurlogy (website NVN) 2017. http://epilepsie. neurologie.nl/cmssite/index.php?pageid=475. Accessed June 2018 .
37. Website of Epilepsy Association Netherlands. http://www.epile psievereniging.nl/eurap-onderzoek-inzicht-in-vrouwen-metepilepsie-en-zwangerschap/. Accessed June 2018.

38. Public website of the Royal Dutch Pharmacists Association (KNMP). http://www.apotheek.nl/. Accessed June 2018.

39. Website of Perined, the perinatal registry of the Netherlands]. https://www.perined.nl/. Accessed June 2018.

40. Mitchell AA, Cottler LB, Shapiro S. Effect of questionnaire design on recall of drug exposure in pregnancy. Am J Epidemiol. 1986;1986(123):670-6.

41. Klungel OH, de BA, Paes AH, Herings RM, Seidell JC, Bakker A. Influence of question structure on the recall of self-reported drug use. J Clin Epidemiol. 2000;53(3):273-7.

42. Jaarboek Zorg 2015 (data on obstetric care in the Netherlands). [website Perined, the perinatal registry of the Netherlands]. https://www.perined.nl/producten/publicaties/jaarboeken. Accessed June 2018

43. Statline Database. Population; educational level; sexe, age, migration background [website Statistics Netherlands] 2017. http:// statline.cbs.nl/Statweb/publication/?DM $=$ SLNL\&PA $=82275$ $\mathrm{NED} \& \mathrm{D} 1=0 \& \mathrm{D} 2=1 \& \mathrm{D} 3=3-4 \& \mathrm{D} 4=0 \& \mathrm{D} 5=0-1,7,11 \& \mathrm{D} 6=9,1$ $4,19,24,29,34,39,44,49,54,59,64,69,1 \& H D R=T, G 1, G 3, G 5 \& S T$ $\mathrm{B}=\mathrm{G} 2, \mathrm{G} 4 \& \mathrm{VW}=\mathrm{T}$. Accessed June 2018.

44. Statline Database. Length and weight of people, underweight and overweight [website Statistics Netherlands] 2017. http://statline. cbs.nl/Statweb/publication/?DM $=$ SLNL $\& \mathrm{PA}=81565$ ned $\& \mathrm{D} 1=0$ $2 \& \mathrm{D} 2=1 \& \mathrm{D} 3=0,6-7 \& \mathrm{D} 4=0 \& \mathrm{D} 5=35 \& \mathrm{HDR}=\mathrm{T} \& \mathrm{STB}=\mathrm{G} 1, \mathrm{G} 2, \mathrm{G}$ 3,G4\&VW=T. Accessed June 2018.

45. van Gelder MM, Bretveld RW, Roukema J, Steenhoek M, van DJ, Spaanderman ME, et al. Rationale and design of the PRegnancy and Infant DEvelopment (PRIDE) Study. Paediatr Perinat Epidemiol. 2013;27(1):34-43.

46. van Gelder MM, Schouten NP, Merkus PJ, Verhaak CM, Roeleveld N, Roukema J. Using web-based questionnaires and obstetric records to assess general health characteristics among pregnant women: a validation study. J Med Internet Res. 2015;17(6):e149.

47. Van Gelder MMHJ, Vorstenbosch S, Derks L, te Winkel B, van Puijenbroek EP, Roeleveld N. Web-based questionnaires to assess perinatal outcome proved to be valid. J Clin Epidemiol. 2017;90:136-43.

48. Van Gelder MMHJ, Vorstenbosch S, te Winkel B, van Puijenbroek EP, Roeleveld N. Using web-based questionnaires to assess medication use during pregnancy: a validation study in 2 prospectively enrolled cohorts. Am J Epidemiol. 2018;187(2):326-36.

49. van Gelder MM, Bretveld RW, Roeleveld N. Web-based questionnaires: the future in epidemiology? Am J Epidemiol. 2010;172(11):1292-8.

50. Bowling A. Mode of questionnaire administration can have serious effects on data quality. J Public Health (Oxf). 2005;27(3):281-91.

51. Pottegard A, Schmidt SA, Wallach-Kildemoes H, Sorensen HT, Hallas J, Schmidt M. Data resource profile: the Danish national prescription registry. Int J Epidemiol. 2017;46(3):798-798f.

52. Pisa FE, Casetta A, Clagnan E, Michelesio E, Vecchi BL, Barbone $\mathrm{F}$. Medication use during pregnancy, gestational age and date of delivery: agreement between maternal self-reports and health database information in a cohort. BMC Pregnancy Childbirth. 2015;15(1):310.

53. Cheung K, El MH, Elfrink ME, Jaddoe VWV, Visser LE, Stricker BHC. The concordance between self-reported medication use and pharmacy records in pregnant women. Pharmacoepidemiol Drug Saf. 2017;26(9):1119-25.

54. Gibson CS, Scott H, Haan E, Scheil W. Age range for inclusion affects ascertainment by birth defects registers. Birth Defects Res A Clin Mol Teratol. 2016;106(9):761-6.

55. Tomson T, Battino D, Bonizzoni E, Craig J, Lindhout D, Perucca $\mathrm{E}$, et al. Comparative risk of major congenital malformations with 
eight different antiepileptic drugs: a prospective cohort study of the EURAP registry. Lancet Neurol. 2018;17(6):530-8.

56. Persson M, Cnattingius S, Villamor E, Soderling J, Pasternak B, Stephansson O, et al. Risk of major congenital malformations in relation to maternal overweight and obesity severity: cohort study of 1.2 million singletons. Brit Med J. 2017;357:j2563.

57. Iessa N, Berard A. Update on prepregnancy maternal obesity: birth defects and childhood outcomes. J Pediatr Genet. 2015;4(2):71-83.

58. Egbe AC. Birth defects in the newborn population: race and ethnicity. Pediatr Neonatol. 2015;56(3):183-8.

59. Hackshaw A, Rodeck C, Boniface S. Maternal smoking in pregnancy and birth defects: a systematic review based on 173687 malformed cases and 11.7 million controls. Hum Reprod Update. 2011;17(5):589-604.

60. Mamluk L, Edwards HB, Savovic J, Leach V, Jones T, Moore THM, et al. Low alcohol consumption and pregnancy and childhood outcomes: time to change guidelines indicating apparently 'safe' levels of alcohol during pregnancy? A systematic review and meta-analyses. BMJ Open. 2017;7(7):e015410.

61. Schimmel MS, Bromiker R, Hammerman C, Chertman L, Ioscovich A, Granovsky-Grisaru S, et al. The effects of maternal age and parity on maternal and neonatal outcome. Arch Gynecol Obstet. 2015;291(4):793-8.

62. Nohr EA, Frydenberg M, Henriksen TB, Olsen J. Does low participation in cohort studies induce bias? Epidemiology. 2006;17(4):413-8.
63. Jacobsen TN, Frydenberg M, Nohr EA. Selection by socioeconomic factors into the Danish National Birth Cohort. Eur J Epidemiol. 2010;25(5):349-55.

64. Nilsen RM, Volsett SE, Gjessing HK, Skjaerven R, Melve KK, Schreuder P, et al. Self-selection and bias in a large prospective pregnancy cohort in Norway. Paediatr Perinat Epidemiol. 2009;23(6):597-608.

65. Nilsen RM, Suren P, Gunnes N, Alsaker ER, Bresnahan M, Hirtz $\mathrm{D}$, et al. Analysis of self-selection bias in a population-based cohort study of autism spectrum disorders. Paediatr Perinat Epidemiol. 2013;27(6):553-63.

66. Odierna DH, Bero LA. Retaining participants in outpatient and community-based health studies: researchers and participants in their own words. Sage Open. 2014;4(4):1-11.

67. Breeze AC, Statham H, Hackett GA, Jessop FA, Lees CC. Attitudes to perinatal postmortem: parental views about research participation. J Med Ethics. 2011;37(6):364-7.

68. EUROmediCAT Steering Group. EUROmediCAT Recommendations for European Pharmacovigilance concerning safety of medication use in pregnancy. Pharmacoepidemiol Drug Saf. 2015;24(Suppl 2):3-7.

69. Thomas SH, Yates LM. Prescribing without evidence-pregnancy. Br J Clin Pharmacol. 2012;74(4):691-7. 